\title{
Resíduo de Polpas de Frutas Desidratadas na Alimentação de Leitões em Fase de Creche ${ }^{1}$ \\ Messias Alves da Trindade Neto², Izabel Marin Petelincar ${ }^{3}$, Dirlei Antônio Berto ${ }^{4}$, José Aparecido Moreira ${ }^{5}$, Dorinha Miriam Silber S. Vitti ${ }^{6}$
}

\begin{abstract}
RESUMO - Avaliou-se química e biologicamente o resíduo de polpa de frutas desidratadas destinadas à indústria de alimentos enriquecidos. No estudo de digestibilidade, foram utilizados 12 leitões castrados, híbridos comerciais, com peso inicial de 12,2 $\pm 1,6 \mathrm{~kg}$, distribuídos individualmente em gaiolas. Os tratamentos foram dieta basal e dieta-teste, com substituição de $30 \%$ da matéria seca na dieta basal. Os resultados da composição química foram: matéria seca, 89,54\%; amido, 71,1\%; glicose, 5,4\%; frutose, 2,2\%; proteína bruta, 5,33\%; energia bruta, $3771 \mathrm{kcal} / \mathrm{kg}$; matéria seca digestível, 96,01\%; energia digestível, $3448 \mathrm{kcal} / \mathrm{kg}$; energia metabolizável, $3389 \mathrm{kcal} / \mathrm{kg}$. O estudo de metabolismo e a análise bromatológica indicaram o resíduo de polpas como alternativa a ser avaliada em dietas de leitões. No ensaio de desempenho, foram utilizados 90 leitões com peso inicial de 6,60 $\pm 0,76 \mathrm{~kg}$, distribuídos em blocos casualizados, com seis repetições e três animais por unidade experimental. Os tratamentos consistiram de níveis de inclusão do resíduo de polpa $(0$, 25, 50, 75 e 100\%) em substituição ao milho da dieta-controle. As fases estudadas foram inicial-1(14 dias), inicial-2 (21 dias) e período total. Não houve diferenças entre os níveis de inclusão estudados sobre as variáveis de desempenho. Em dieta farelada, o resíduo de polpa de frutas desidratadas pode substituir totalmente o milho.
\end{abstract}

Palavras-chave: alimento alternativo, desmamados, digestibilidade, metabolizabilidade

\section{Powdered Fruits Pulp Residue in the Piglets Feeding in the Nursery Phase}

\begin{abstract}
It was evaluated chemically and biologically the powdered fruits pulp residue, used in human food industry. In the digestibility study it was used 12 commercial hybrids barrows piglets, with initial weight $12,2 \pm 1,6 \mathrm{~kg}$, allotted in individual cages. The treatments were a basal and a test diet. In the test diet the fruits pulp residue replaced $30 \%$ of the basal dry matter. The following values were obtained: dry matter $89,54 \%$, starch $71,1 \%$, glucose $5,4 \%$, fructose $2,2 \%$, crude protein $5,33 \%$, gross energy $3771 \mathrm{kcal} / \mathrm{kg}$, apparent digestible dry matter $96,01 \%$, digestible energy $3448 \mathrm{kcal} / \mathrm{kg}$, metabolizable energy $3389 \mathrm{kcal} / \mathrm{kg}$. By bromatologic results and metabolism study, the powdered fruits pulp residue was characterized as an alternative to be evaluated in piglet diets. In the performance assay 90 piglets with initial weight of $6,60 \pm 0,76 \mathrm{~kg}$ were allotted in a randomized block design, with six replications and three animals per experimental unit. The treatments were levels of powdered fruits pulp residue $(0,25,50,75$ and $100 \%)$ replacing the corn of the control diet. The studied phases were initial-1 (14 days), initial-2 (21 days) and total period. On the performance there was no difference between the studied inclusion levels. For meal diets, the fruits pulp residue can replace the corn.
\end{abstract}

Key Words: alternative food, digestibilite, metabolizabilite, performance, weaned

\section{Introdução}

As oscilações de preços dos grãos, decorrentes das demandas nos mercados interno e externo, tornam a alimentação determinante na rentabilidade obtida pelo suinocultor, visto que o custo final de produção, na atividade comercial, varia, sobretudo, em função dos preços do milho e do farelo de soja. Tais oscilações, impostas pelos mercados, podem resultar em prejuízos significativos aos produtores, pois, em alguns casos, produtores comerciais são obrigados a reduzirem e ou extinguirem seus plantéis.

Uma das possibilidades de redução dos efeitos dessas situações sazonais na suinocultura comercial é reduzir o custo das dietas empregadas nos diversos ciclos de criação do suíno. No caso da alimentação de leitões, o estudo de ingredientes alternativos em dietas para os períodos pós-desmame tem recebido considerável importância dos nutricionistas, na perspectiva de maximização do potencial genético

\footnotetext{
1 Projeto financiado pela FAPESP - Processo 01/05168-0.

2 Professor Doutor do Departamento de Nutrição e Produção Animal da FMVZ-USP, Campus de Pirassununga, Rua Duque de Caxias Norte, 225, CEP: 13630-000 - Pirassununga - SP - Brasil.

${ }^{3}$ Instituto de Zootecnia, R. Heitor Penteado 56, Nova Odessa, SP, Brasil, CEP: 13460-000.

4 Professor Doutor do Departamento de Produção e Exploração Animal, FMVZ, UNESP/Botucatu, SP.

5 Aluno de pós-graduação do Centro de Energia Nuclear na Agricultura-ESALQ-USP, Piracicaba, SP.

6 Professora Doutora do CENA - ESALQ-USP, Piracicaba, SP.
} 
nas fases iniciais de crescimento, que refletirá na fase de terminação.

Entre as possibilidades apontadas pela pesquisa, os resíduos e/ou subprodutos das indústrias alimentícias têm sido apresentados como possíveis substitutos dos ingredientes protéicos e energéticos mais utilizados e de maior custo na formulação de rações (EMBRAPA, 1991; Trindade Neto et al., 1994; Gomes et al., 1998; Barbosa et al., 1999a; Bertol \& Ludke, 1999; Furlan et al., 2001). Além dos subprodutos da indústria de alimentos, destacam-se os provenientes de abatedouros e encubatórios e da indústria alcooleira como alternativas dietéticas viáveis para o suíno nas diversas fases do desenvolvimento (Nutritional Research Council, 1998; AMIPIG, 2000; Rostagno et al., 2000; Bellaver, 2001; Butolo, 2001).

O resíduo de polpas de frutas desidratadas (RPFD) é um subproduto industrial de alimentos da linha humana. Origina-se, principalmente, de polpas de maçã, mamão e banana, destinadas à produção de alimentos enriquecidos, conhecidos como "matinais". As frutas usadas para esse fim são cortadas transversalmente em fatias de aproximadamente $2 \mathrm{~mm}$ de espessura, as sementes são retiradas e as fatias secas. $O$ processo de secagem ocorre em forno de fluxo contrário de ar quente, com auxílio de um exaustor na entrada e queimadores na saída, aquecido a gás metano à temperatura de $90^{\circ} \mathrm{C}$. O tempo de secagem varia de acordo com a fruta. Após a desidratação, as fatias são reduzidas a flocos em moinho de cilindros com "dentes". Para esse processamento é necessária a adição de farinha de arroz, para evitar aderência do produto aos cilindros, em razão dos açúcares existentes nas frutas. Em seguida, procede-se o peneiramento para obtenção dos flocos das frutas, originando o resíduo de polpas de frutas desidratadas (RPFD), que é uma mistura de farinha de arroz e pequenas partículas de fruta, com aroma e sabor agradáveis.

A partir dessas características e de prévia análise bromatológica, avaliou-se química e biologicamente o RPFD como alimento alternativo na substituição do milho em dietas para leitões nas fases iniciais de creche.

\section{Material e Métodos}

O estudo foi realizado na unidade de suínos do Instituto de Zootecnia, em Nova Odessa, SP.

No primeiro ensaio experimental, após análise bromatológica, determinaram-se os valores digestíveis e metabolizáveis do resíduo de polpas de frutas desidratadas (RPFD). Foram utilizados 12 leitões machos castrados, provenientes de cruzamentos entre reprodutores e matrizes comerciais, com peso inicial de 12,2 $\pm 1,6 \mathrm{~kg}$. Os animais foram alojados em gaiolas de estudos metabólicos semelhantes às descritas por Pekas (1968). O período experimental foi de doze dias - sete para adaptação às instalações e às dietas e cinco para coleta de fezes e urina.

A unidade de digestibilidade foi construída em alvenaria, com dimensões de 20 × 6 m, pé-direito de $3 \mathrm{~m}$, com todos os lados fechados e laterais com janelas tipo vitral revestidas com vidros e internamente forradas com isopor, para isolamento térmico. O espaço foi equipado com três condicionadores de ar, do tipo "Split System", modelo RAS 402CS + RAS 403AC, com condensação de ar e capacidade de 4,0 TR (tonelada de refrigeração/hora - 1 TR $=12000$ $\mathrm{BTU}$ ), permitindo que a temperatura média não ultrapassasse $22 \pm 2{ }^{\circ} \mathrm{C}$.

Os tratamentos consistiram de dieta-referência (Tabela 1), composta de milho, farelo de soja, produto lácteo e vitaminas, e dieta-teste, com a inclusão de RPFD em substituição a $30 \%$ da matéria seca na referência, com suplementação equivalente de minerais e vitaminas.

Cada animal recebeu a mesma quantidade diária de dieta, na base da matéria seca, por unidade de tamanho metabólico (peso corporal $\mathrm{kg}^{0,75}$ ), segundo a fórmula de Matterson et al. (1965). As técnicas de manejo, coleta de fezes e urina foram feitas segundo Colnago (1979) e Trindade Neto et al. (1994).

O delineamento adotado foi blocos ao acaso, com seis repetições por tratamento e um animal por unidade experimental. Os coeficientes de digestibilidade na matéria seca, valores da energias digestível e metabolizável foram submetidos à análise de variância e as diferenças entre médias, comparadas pelo teste $\mathrm{F}$.

No ensaio de desempenho, o RPFD foi avaliado como alternativa de substituição do milho nas dietas. As fases consideradas no estudo foram inicial-1 (21 aos 35 dias de idade) inicial-2 (36 aos 56 dias de idade) e período total de creche ( 21 aos 56 dias de idade). Foram utilizados 90 leitões (45 machos castrados e 45 fêmeas, desmamados na terceira semana de idade) provenientes de cruzamentos entre reprodutores e matrizes comerciais.

A unidade de creche foi construída em alvenaria, com pé-direito de $3,20 \mathrm{~m}$ e janelas do tipo vitral revestidas com vidro, para auxiliar no controle da ventilação. Internamente, foi equipada com cinco ventiladores giratórios de parede e baias coletivas

R. Bras. Zootec., v.33, n.5, p.1254-1262, 2004 
construídas em estrutura metálica, com piso plástico vazado, instalado a $80 \mathrm{~cm}$ do piso do galpão. As baias, medindo $1,00 \times 2,00 \mathrm{~m}$, possuíam comedouros metálicos semi-automáticos, bebedouros do tipo chupeta e aquecedores de resistência elétrica. Dois termômetros de máxima e mínima foram instalados (um em cada ala) na altura do piso das baias. As leituras diárias determinavam o controle de funcionamento dos aquecedores e ventiladores, procurando-se atender às demandas de temperatura ambiente, conforme a fase de desenvolvimento dos leitões.

O delineamento utilizado foi de blocos ao acaso com cinco tratamentos e seis repetições. Adotando-se o peso inicial como referência na formação dos blocos, a unidade experimental foi constituída de três animais com $6,6 \pm 0,76 \mathrm{~kg}$.

Os tratamentos, definidos com base no ensaio de digestibilidade e metabolismo, foram níveis de inclusão $(0,25,50,75$ e $100 \%)$ do RPFD em substituição ao milho, estão apresentados na Tabela 2 e $3 . \mathrm{Na}$ elaboração das dietas, procurou-se atender às exigências nutricionais de cada fase, prescritas pelo NRC (1998).

O controle experimental ocorreu ao final de cada fase, quando aferiram-se o peso vivo, ganho em peso, o consumo de ração e a conversão alimentar. Os dados de desempenho foram submetidos à análise de regressão por polinômios ortogonais, por meio do pacote computacional SAS (1993), conforme o modelo:

$$
\mathrm{Y}_{\mathrm{ij}}=\mu+\mathrm{N}_{\mathrm{i}}+\mathrm{B}_{\mathrm{j}}+\mathrm{e}_{\mathrm{ij}}
$$

em que: $Y_{\mathrm{ij}}=$ constante associada a todas observações; $\mu=$ média geral da variável; $\mathrm{N}_{\mathrm{i}}=$ efeito do nível $\mathrm{i}$ do RPFD, sendo $i=0,25,50,75$ e $100 \% ; B_{j}=$ efeito do bloco $\mathrm{j}$, sendo $\mathrm{j}=1,2, \ldots$ e 6 ; $\mathrm{e}_{\mathrm{ij}}=$ erro aleatório associado a cada observação.

Uma vez que não foram observadas diferenças significativas entre os tratamentos nas variáveis de desempenho, foi calculada a relação entre ganho de peso dos leitões. Essa relação foi obtida com a divisão dos resultados afins às dietas que continham o RPFD pelo ganho obtido com o tratamento sem a inclusão do ingrediente-teste, determinando-se, numericamente, a diferença porcentual entre as respostas obtidas.

\section{Resultados e Discussão}

Os resultados de composição química, digestibilidade e metabolizabilidade do RPFD são apresentados na Tabela 4. Trata-se de um alimento energético, em virtude do baixo nível protéico e das relações entre as frações da energia constituinte (Bondi, 1988; Trindade Neto et al., 2002).

Com base nos dados bromatológicos obtidos no ensaio de digestibilidade e metabolismo, o RPFD caracterizou-se como um ingrediente alternativo para

Tabela 1 - Composição centesimal da ração-referência Table 1 - Percentage composition of the reference diet

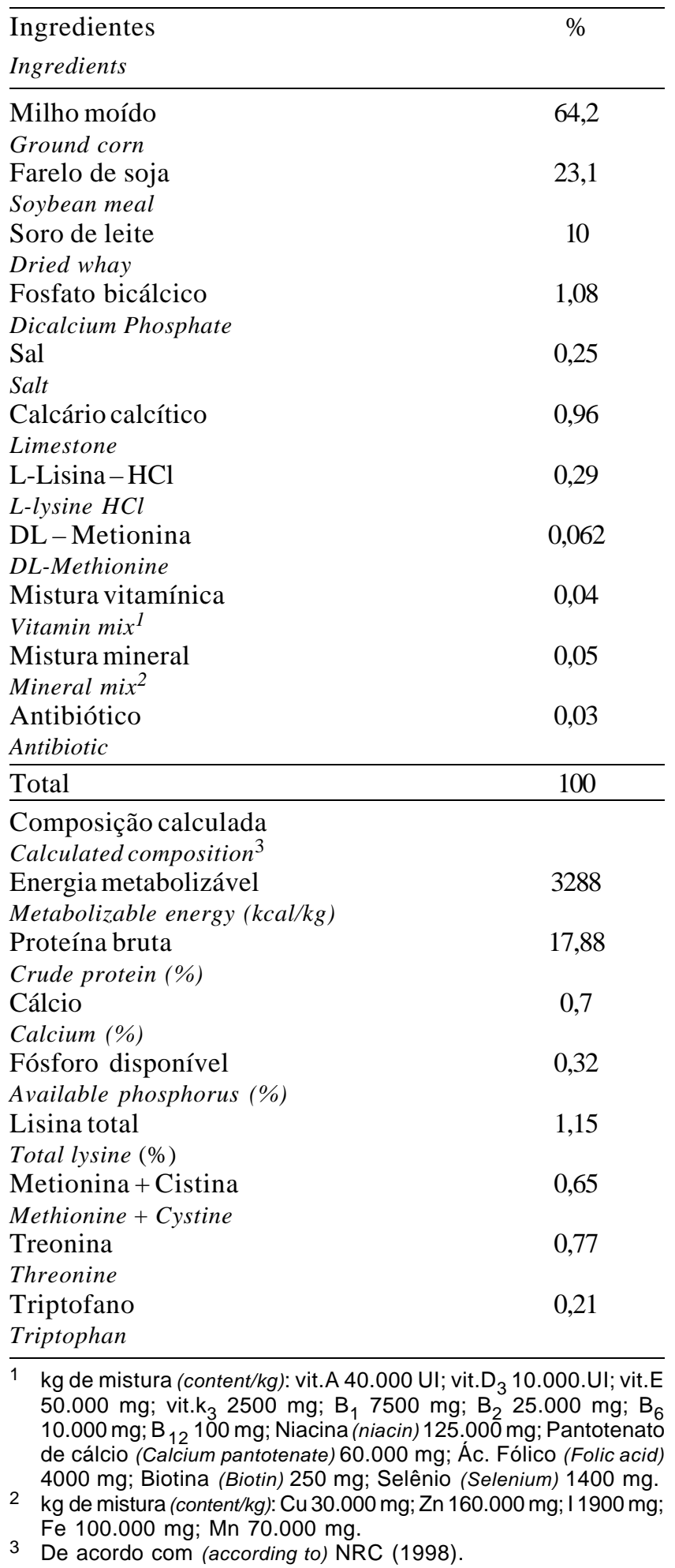


Tabela 2 - Composição centesimal das dietas experimentais, fase inicial-1

Table 2 - Percentage composition of the experimental diets, initial-1 phase

Ingredientes $\quad$ Substituição do milho pelo ingrediente teste (\%)

Ingredient

Corn substituition by test

\begin{tabular}{|c|c|c|c|c|c|}
\hline & 0 & 25 & 50 & 75 & 100 \\
\hline $\begin{array}{l}\text { Resíduo de polpa de frutas desidratadas } \\
\text { Powdered fruits pulp residue }\end{array}$ & - & 12,5 & 25 & 38,08 & 50,37 \\
\hline $\begin{array}{l}\text { Milho comum } \\
\text { Common corn }\end{array}$ & 50,78 & 37,19 & 23,49 & 9,32 & - \\
\hline $\begin{array}{l}\text { Farelo de Soja } \\
\text { Soybean meal }\end{array}$ & 21,04 & 22,19 & 23,36 & 24,54 & 21,12 \\
\hline $\begin{array}{l}\text { Produto lácteo } \\
\text { Milk product }\end{array}$ & 10 & 10 & 10 & 10 & 10 \\
\hline $\begin{array}{l}\text { Soro de leite } \\
\text { Dried whay }\end{array}$ & 15 & 15 & 15 & 15 & 15 \\
\hline $\begin{array}{l}\text { Fosfato bicálcico } \\
\text { Dicalcim phosphate }\end{array}$ & 1,03 & 1,02 & 1,06 & 1,0 & 1,03 \\
\hline $\begin{array}{l}\text { Calcário calcítico } \\
\text { Limestone }\end{array}$ & 0,8 & 0,78 & 0,76 & 0,74 & 0,74 \\
\hline $\begin{array}{l}\text { Sal } \\
\text { Salt }\end{array}$ & 0,17 & 0,17 & 0,17 & 0,17 & 0,17 \\
\hline $\begin{array}{l}\text { Lisina }-\mathrm{HCl} \\
\mathrm{L}-\text { lysine } \mathrm{HCl}\end{array}$ & 0,6 & 0,556 & 0,554 & 0,551 & 0,692 \\
\hline $\begin{array}{l}\text { DL-Metionina } \\
\text { DL-Methionine }\end{array}$ & 0,213 & 0,240 & 0,273 & 0,305 & 0,376 \\
\hline $\begin{array}{l}\text { L - Triptofano } \\
\text { L - Tryptophan }\end{array}$ & 0,07 & 0,062 & 0,063 & 0,064 & 0,089 \\
\hline $\begin{array}{l}\text { L-Treonina } \\
L \text { - Threonine }\end{array}$ & 0,2 & 0,204 & 0,225 & 0,135 & 0,326 \\
\hline $\begin{array}{l}\text { Suplemento vitamínico } \\
\text { Vitamin mix }\end{array}$ & 0,04 & 0,04 & 0,04 & 0,04 & 0,04 \\
\hline $\begin{array}{l}\text { Suplemento mineral } \\
\text { Mineral mix }\end{array}$ & 0,05 & 0,05 & 0,05 & 0,05 & 0,05 \\
\hline $\begin{array}{l}\text { Total } \\
\text { Total }\end{array}$ & 100 & 100 & 100 & 100 & 100 \\
\hline
\end{tabular}

Composição calculada

Calculated composition

\begin{tabular}{|c|c|c|c|c|c|}
\hline Proteína bruta (\%) & 18 & 18 & 18 & 18 & 16,2 \\
\hline Crude protein & & & & & \\
\hline Energia metabolizável (kcal/kg) & 3450 & 3445 & 3438 & 3435 & 3424 \\
\hline Metabolizable energy & & & & & \\
\hline Cálcio (\%) & 0,8 & 0,8 & 0,8 & 0,8 & 0,8 \\
\hline $\begin{array}{l}\text { Calcium } \\
\text { Fósforo total (\%) }\end{array}$ & 0,6 & 0,59 & 0,57 & 0,56 & 0,53 \\
\hline $\begin{array}{l}\text { Total phosphorus } \\
\text { Fósforo disponível (\%) }\end{array}$ & 0,4 & 0,4 & 0,4 & 0,4 & 0,4 \\
\hline $\begin{array}{l}\text { Available phosphorus } \\
\text { Lisina total }(\%) \\
\text { Total lysine }\end{array}$ & 1,3 & 1,3 & 1,3 & 1,3 & 1,3 \\
\hline $\begin{array}{l}\text { Metionina + Cistina } \\
\text { Methionine + Cystine }\end{array}$ & 0,74 & 0,74 & 0,74 & 0,74 & 0,74 \\
\hline $\begin{array}{l}\text { Triptofano total } \\
\text { Total tryptophan }\end{array}$ & 0,24 & 0,24 & 0,24 & 0,24 & 0,24 \\
\hline $\begin{array}{l}\text { Treonina total } \\
\text { Total threonine }\end{array}$ & 0,80 & 0,80 & 0,80 & 0,80 & 0,80 \\
\hline
\end{tabular}

${ }^{1}$ Níveis de garantia (Guarantee levels): gordura (fat) $28,5 \%$; proteína bruta (crude protein) 17,2\%; lactose $40 \%$; fibra bruta (crude fiber) 0,2\%; cinzas (ash) 7,5\%; umidade (moisture) 2,5\%; Ca 0,55\%; P 0,60\%; Na 0,85\%; K 1,35\%; Fe 15 ppm; lisina digestível (digestible lysine) 1,02\%; metionina + cistina digestível (digestible methionine + cystine) 0,60\%; treonina digestível (digestible threonine) 0,84\%; triptofano digestível (digestible tryptophan) 0,18\%; energia metabolizável (metabolizable energy) $5625 \mathrm{kcal} / \mathrm{kg}$.

2 kg de mistura (content/kg): vit.A 40.000 UI; vit.D $10.000 . U I ;$ vit.E 50.000 mg; vit. $\mathrm{k}_{3} 2500$ mg; $\mathrm{B}_{1} 7500$ mg; $\mathrm{B}_{2}$ 25.000 mg; $B_{6} 10.000$ mg; $B_{12} 100$ mg; Niacina (niacin) 125.000 mg; Pantotenato de cálcio (Calcium panthotenate) 60.000 mg; Ác. fólico (Folic acid) 4000 mg; Biotina (Biotin) 250 mg; Selênio (Selenium) 1400 mg.

${ }^{3} \mathrm{~kg}$ de mistura (content/kg): Cu 30.000 mg; Zn 160.000 mg; I 1900 mg; Fe 100.000 mg; Mn 70.000 mg. 
Tabela 3 - Composição centesimal das dietas experimentais, fase inicial-2

Table 3 - Percentage composition of the experimental diets, initial-2 phase

\begin{tabular}{|c|c|c|c|c|c|}
\hline \multirow[t]{2}{*}{$\begin{array}{l}\text { Ingredientes } \\
\text { Ingredient }\end{array}$} & \multicolumn{5}{|c|}{$\begin{array}{c}\text { Substituição do milho pelo ingrediente-teste (\%) } \\
\text { Corn substituition by test }\end{array}$} \\
\hline & 0 & 25 & & 75 & 100 \\
\hline $\begin{array}{l}\text { Resíduo de polpa de frutas desidratadas } \\
\text { Powdered fruits pulp residue }\end{array}$ & - & 16,42 & 32,8 & 49,27 & 60,85 \\
\hline Milho comum & 65,7 & 48,3 & 31 & 13,6 & 0 \\
\hline $\begin{array}{l}\text { Common corn } \\
\text { Farelo de soja } \\
\text { Soybean meal }\end{array}$ & 22,33 & 23,33 & 24,136 & 25 & 27 \\
\hline $\begin{array}{l}\text { Produto lácteo } \\
\text { Milk product }\end{array}$ & 4 & 4 & 4 & 4 & 4 \\
\hline $\begin{array}{l}\text { Soro de leite } \\
\text { Dried whay }\end{array}$ & 5 & 5 & 5 & 5 & 5 \\
\hline $\begin{array}{l}\text { Fosfato bicálcico } \\
\text { Dicalcim phosphate }\end{array}$ & 1,17 & 1,062 & 1,16 & 1,156 & 1,14 \\
\hline $\begin{array}{l}\text { Calcário calcítico } \\
\text { Limestone }\end{array}$ & 0,74 & 0,723 & 0,69 & 0,667 & 0,65 \\
\hline $\begin{array}{l}\text { Sal } \\
\text { Salt }\end{array}$ & 0,3 & 0,3 & 0,3 & 0,3 & 0,3 \\
\hline $\begin{array}{l}\text { Lisina }-\mathrm{HCl} \\
\mathrm{L} \text { - lysine } \mathrm{HCl}\end{array}$ & 0,418 & 0,434 & 0,449 & 0,462 & 0,436 \\
\hline $\begin{array}{l}\text { DL-Metionina } \\
\text { DL-Methionine }\end{array}$ & 0,113 & 0,16 & 0,205 & 0,252 & 0,273 \\
\hline $\begin{array}{l}\text { L - Triptofano } \\
\text { L- Tryptophan }\end{array}$ & 0,033 & 0,036 & 0,041 & 0,045 & 0,041 \\
\hline $\begin{array}{l}\text { L- Treonina } \\
L \text { - Threonine }\end{array}$ & 0,111 & 0,15 & 0,185 & 0,221 & 0,229 \\
\hline $\begin{array}{l}\text { Suplemento vitamínico } \\
\text { Vitamin mix }\end{array}$ & 0,03 & 0,03 & 0,03 & 0,03 & 0,03 \\
\hline $\begin{array}{l}\text { Suplemento mineral } \\
\text { Mineral mix }\end{array}$ & 0,05 & 0,05 & 0,05 & 0,05 & 0,05 \\
\hline $\begin{array}{l}\text { Total } \\
\text { Total }\end{array}$ & 100 & 100 & 100 & 100 & 100 \\
\hline
\end{tabular}

Composição calculada

Calculated composition

\begin{tabular}{|c|c|c|c|c|c|}
\hline Proteína bruta (\%) & 18 & 17,94 & 18 & 18 & 18,5 \\
\hline Crude protein & & & & & \\
\hline Energia metabolizável (kcal/kg) & 3340 & 3333 & 3322 & 3314 & 3276 \\
\hline Metabolizable energy & & & & & \\
\hline Cálcio (\%) & 0,7 & 0,7 & 0,7 & 0,7 & 0,7 \\
\hline Calcium & & & & & \\
\hline Fósforo total(\%) & 0,57 & 0,55 & 0,53 & 0,5 & 0,49 \\
\hline Total phosphorus & & & & & \\
\hline Fósforo disponível (\%) & 0,32 & 0,32 & 0,32 & 0,32 & 0,32 \\
\hline Available phosphorus & & & & & \\
\hline Lisina total $(\%)$ & 1,11 & 1,11 & 1,11 & 1,11 & 1,11 \\
\hline Total lysine & & & & & \\
\hline Metionina + Cistina & 0,63 & 0,63 & 0,63 & 0,63 & 0,63 \\
\hline $\begin{array}{l}\text { Methionine + Cystine } \\
\text { Triptofano total }\end{array}$ & 0,2 & 0,2 & 0,2 & 0,2 & 0,2 \\
\hline Total triptophan & & & & & \\
\hline Treonina total & 0,68 & 0,68 & 0,68 & 0,68 & 0,68 \\
\hline
\end{tabular}

${ }^{1}$ Níveis de garantia (Guarantee levels): gordura (fat) 28,5\%; proteína bruta (crude protein) 17,2\%; lactose $40 \%$; fibra bruta (crude fiber) 0,2\%; cinzas (ash) 7,5\%; umidade (moisture) 2,5\%; Ca 0,55\%; P 0,60\%; Na 0,85\%; K 1,35\%; Fe 15 ppm; lisina digestível (digestible lysine) 1,02\%; metionina + cistina digestível (digestible methionine + cystine) 0,60\%; treonina digestível (digestible threonine) 0,84\%; triptofano digestível (digestible tryptophan) 0,18\%; energia metabolizável (metabolizable energy) $5625 \mathrm{kcal} / \mathrm{kg}$.

${ }^{2} \mathrm{~kg}$ de mistura (content/kg): vit.A 40.000 UI; vit. $D_{3}$ 10.000.UI; vit.E 50.000 mg; vit. $\mathrm{k}_{3} 2500$ mg; $\mathrm{B}_{1} 7500$ mg; $\mathrm{B}_{2}$ $25.000 \mathrm{mg} ; \mathrm{B}_{6} 10.000 \mathrm{mg} ; \mathrm{B}_{12} 100 \mathrm{mg}$; Niacina (niacin) $125.000 \mathrm{mg}$; Pantotenato de cálcio (Calcium panthotenate) $60.000 \mathrm{mg}$; Ác. fólico (Folic acid) 4000 mg; Biotina (Biotin) 250 mg; Selênio (Selenium) $1400 \mathrm{mg}$.

${ }^{3} \mathrm{~kg}$ de mistura (content/kg): Cu 30.000 mg; Zn 160.000 mg; I 1900 mg; Fe 100.000 mg; Mn 70.000 mg. 
a alimentação de leitões em comparação com o milho.

Quanto à composição química e aos valores digestíveis e metabolizáveis do RPFD, constata-se que a elevada concentração de amido deve-se a presença da farinha de arroz proveniente do processo de moagem das polpas de frutas desidratadas. Os demais açúcares (mono e dissacarídeos) são provenientes das partículas de frutas não-retidas nas peneiras. Os valores de energias digestível e metabolizável assemelham-se aos do milho e estão acima da farinha de arroz, segundo NRC (1998).

Durante o estudo de metabolismo, pôde-se observar a fácil aceitação do ingrediente em teste, graças ao agradável aroma e ao sabor adocicado, atribuídos à presença de açúcares. O suíno possui grande sensibilidade olfativa e gustativa (Patience et al., 1995), sobretudo nas primeiras fases de crescimento, quando as papilas gustativas são mais desenvolvidas (Veum, 1991). Resposta semelhante em relação à aceitação de produto adocicado foi observada por Barbosa et al. (1999a), que determinaram digestibilidade e valores energéticos de resíduo de bolacha com leitões em fase inicial de crescimento.

$\mathrm{Na}$ avaliação do desempenho, a substituição do milho por níveis crescentes de RPFD nas rações não afetou $(\mathrm{P}>0,05)$ o ganho de peso, o consumo de ração e a conversão alimentar, em todas as fases do ensaio experimental, conforme é apresentado na Tabela 5.

Na fase inicial-1, a substituição do milho por $75 \%$ do RPFD, em valores matemáticos, proporcionou $25 \%$ de ganho de peso e $14 \%$ no consumo de ração, em comparação à dieta-controle. A eficiência na utilização da dieta com 75\% de RPFD refletiu, positivamente, na conversão alimentar, que, embora não tenha diferido $(\mathrm{P}>0,05)$ dos demais tratamentos, ficou 6\% abaixo do controle. Essas respostas confirmam o melhor valor da fração metabolizável da energia contida no RPFD, comparada à do milho e da farinha de arroz, obtido pela relação energia metabolizável:energia digestível, de $98,29 \%$ para o RPFD, $97 \%$ para o milho e $94 \%$ para farinha de arroz.

A maior relação energia metabolizável:energia digestível decorre das características bioquímicas dos carboidratos presentes no alimento, sendo fundamental para o leitão nas fases iniciais de crescimento. A predominância do amido (polissacarídeo) nas dietas à base de cereais torna-se limitante para a capacidade digestiva do leitão recém-desmamado, quando oferecidas em substituição ao leite da porca que é altamente digestível. Por outro lado, a presença de açúcares simples, como a glicose e frutose (monossacarídeos) e lactose (dissacarídeos), favorece a ação enzimática e o processo digestivo do leitão no período pós-desmame. Em decorrência de limitações fisiológicas e digestivas do suíno nas primeiras semanas, por ocasião do desmame antecipado, como ocorreu no presente estudo, as características das dietas e dos carboidratos presentes, provavelmente, influenciaram as condições qualiquantitativas das produções enzimática, pancreática e intestinal do leitão, conforme Kidder \& Manners (1978) e Pekas (1991).

Quando houve substituição integral do milho pelo

Tabela 4 - Composição química e valores energéticos do resíduo de polpa de frutas desidratado

Table 4 - Chemical composition and energy values of powdered fruits pulp residue

\begin{tabular}{|c|c|}
\hline Matéria seca $(\%)^{1}$ & 89,54 \\
\hline Dry matter & \\
\hline Proteína bruta $(\%)^{1}$ & 5,33 \\
\hline Crude protein & \\
\hline Energia bruta $(\mathrm{kcal} / \mathrm{kg})^{1}$ & 3771 \\
\hline Crude energy & \\
\hline $\operatorname{Amido}(g / 100 g)^{2}$ & $71,1 \pm 1,4$ \\
\hline Starch & \\
\hline Sacarose $(g / 100 g)^{2}$ & $0,1 \pm 0,0$ \\
\hline Sucrose & \\
\hline Glicose $(g / 100 g)^{2}$ & $5,4 \pm 0,1$ \\
\hline $\begin{array}{l}\text { Glucose } \\
\text { Frutose }(\mathrm{g} / 100 \mathrm{~g})^{2}\end{array}$ & $2,2 \pm 0,0$ \\
\hline Frutose & \\
\hline Matéria seca digestível (\%) & 96,01 \\
\hline Digestible dry matter & \\
\hline Coeficiente de digestibilidade da proteína (\%) & 77,55 \\
\hline Coefficient of apparent digestibility of crude protein & \\
\hline Proteína digestível $(\%)$ & 4,11 \\
\hline Digestible protein & \\
\hline Energia digestível (kcal/kg) & 3448 \\
\hline Digestible energy & \\
\hline Energia metabolizável (kcal/kg) & 3389 \\
\hline Metabolizable energy & \\
\hline Energia digestível/energia bruta $(\%)$ & 91,43 \\
\hline Digestible energy/crude energy & \\
\hline Energia metabolizável/energia bruta $(\%)$ & 89,87 \\
\hline $\begin{array}{l}\text { Metabolizable energy/crude energy } \\
\text { Energia metabolizável/energia digestível }(\%) \\
\text { Metabolizable energy/digestible energy }\end{array}$ & 98,29 \\
\hline $\begin{array}{l}{ }^{1} \text { Análises realizadas no Laboratório de Bromatologi } \\
\text { de Zootecnia. } \\
{ }^{1} \text { Analyses were performed at the Bromatologic Laboratory } \\
\text { Zootecnia. } \\
2 \text { Determinações feitas no Centro de Química de } \\
\text { Instituto de Tecnologia de Alimentos - ITAL. } \\
{ }^{2} \text { Analyses performed at the Foods Chemical Centre } \\
\text { Tecnologia de Alimentos - ITAL. }\end{array}$ & $\begin{array}{l}\text { do Instituto } \\
\text { of Instituto de } \\
\text { limentos do } \\
\text { I Instituto de }\end{array}$ \\
\hline
\end{tabular}


Tabela 5 - Efeitos dos níveis de resíduo de polpa de frutas desidratadas no desempenho médio diário dos leitões ${ }^{1}$

Table 5 - Effects of powdered fruits pulp residue levels on average daily performance of piglets ${ }^{1}$

\begin{tabular}{lll}
\hline Parâmetros & Níveis do resíduo de polpa de frutas desidratadas $(\%)^{2}$ & CV\%
\end{tabular}

Parameters

Powdered fruits pulp residue levels

\begin{tabular}{|c|c|c|c|c|c|c|}
\hline \multirow[b]{3}{*}{ Peso médio inicial $(\mathrm{kg})$} & 0 & 25 & 50 & 75 & 100 & \\
\hline & \multicolumn{5}{|c|}{$\begin{array}{l}\text { Fase inicial-1: } 21 \text { aos } 35 \text { dias de idade } \\
\text { Initial phase-1:21 at } 35 \text { days of age }\end{array}$} & \\
\hline & 6,989 & 6,989 & 7,011 & 6,993 & 6,994 & 0,3 \\
\hline Initial average weight & & & & & & \\
\hline $\begin{array}{l}\text { Peso médio final }(\mathrm{kg}) \\
\text { Final average weight }\end{array}$ & 9,689 & 10,072 & 10,056 & 10,383 & 9,861 & 6,7 \\
\hline $\begin{array}{l}\text { Ganho de peso }(\mathrm{kg} / \mathrm{dia}) \\
\text { Weight gain (kg/day) }\end{array}$ & 0,208 & 0,237 & 0,234 & 0,261 & 0,220 & 22,3 \\
\hline $\begin{array}{l}\text { Relação de ganho }(\mathrm{kg} / \mathrm{kg})^{3} \\
\text { Weight: weight ratio }\end{array}$ & 1,00 & 1,14 & 1,13 & 1,25 & 1,06 & - \\
\hline $\begin{array}{l}\text { Consumo de ração }(\mathrm{kg} / \mathrm{dia}) \\
\text { Feed intake ( } \mathrm{kg} / \text { day })\end{array}$ & 0,291 & 0,319 & 0,322 & 0,331 & 0,315 & 18,7 \\
\hline $\begin{array}{l}\text { Consumo de glicose }(\mathrm{g} / \mathrm{dia})^{4} \\
\text { Glucose intake (g/day) }\end{array}$ & 0 & 2,2 & 4,4 & 7,0 & 8,6 & - \\
\hline $\begin{array}{l}\text { Consumo de frutose }(\mathrm{g} / \mathrm{dia})^{4} \\
\text { Frutose intake }(\mathrm{g} / \text { day })\end{array}$ & 0 & 0,9 & 2,0 & 3,0 & 3,5 & - \\
\hline $\begin{array}{l}\text { Conversão alimentar } \\
\text { Feed: gain ratio }\end{array}$ & 1,41 & 1,37 & 1,38 & 1,32 & 1,45 & 12,6 \\
\hline
\end{tabular}

Feed: gain ratio

Fase inicial-2: 36 aos 56 dias de idade

Initial phase-2: 36 at 56 days of age

\begin{tabular}{|c|c|c|c|c|c|c|}
\hline Peso médio inicial (kg) & 9,689 & 10,072 & 10,056 & 10,383 & 9,861 & 6,7 \\
\hline Initial average weight & & & & & & \\
\hline Peso médio final (kg) & 20,067 & 21,000 & 21,472 & 21,361 & 20,306 & 8,2 \\
\hline \multicolumn{7}{|l|}{ Final average weight } \\
\hline Ganho de peso (kg/dia) & 0,494 & 0,520 & 0,544 & 0,523 & 0,497 & 11,2 \\
\hline \multicolumn{7}{|l|}{ Weight gain (kg/day) } \\
\hline Relação de ganho $(\mathrm{kg} / \mathrm{kg})^{3}$ & 1,00 & 1,05 & 1,10 & 1,06 & 1,01 & - \\
\hline \multicolumn{7}{|l|}{ Weight: weight ratio } \\
\hline Consumo de ração (kg/dia) & 0,773 & 0,792 & 0,858 & 0,862 & 0,804 & 10,0 \\
\hline \multicolumn{7}{|l|}{ Feed intake ( $\mathrm{kg} /$ day) } \\
\hline Consumo de glicose $(\mathrm{g} / \mathrm{dia})^{4}$ & 0 & 7,0 & 15,2 & 23,0 & 26,4 & - \\
\hline \multicolumn{7}{|l|}{ Glucose intake (g/day) } \\
\hline Consumo de frutose $(\mathrm{g} / \mathrm{dia})^{4}$ & 0 & 3,0 & 6,0 & 9,3 & 11,0 & - \\
\hline \multicolumn{7}{|l|}{ Frutose intake (g/day) } \\
\hline Conversão alimentar & 1,57 & 1,52 & 1,58 & 1,65 & 1,62 & 6,7 \\
\hline Feed: gain ratio & & & & & & \\
\hline
\end{tabular}

Feed: gain ratio

Período total: 21 aos 56 dias de idade

Total period: 21 at 56 days of age

\begin{tabular}{|c|c|c|c|c|c|c|}
\hline Ganho de peso (kg/dia) & 0,385 & 0,412 & 0,425 & 0,422 & 0,391 & 12,3 \\
\hline $\begin{array}{l}\text { Weight gain ( } \mathrm{kg} / \text { day) } \\
\text { Relação de ganho }(\mathrm{kg} / \mathrm{kg})^{3}\end{array}$ & 1,000 & 1,070 & 1,104 & 1,096 & 1,016 & - \\
\hline $\begin{array}{l}\text { Weight: weight ratio } \\
\text { Consumo de racão }(\mathrm{kg} / \mathrm{dia})\end{array}$ & 0,580 & 0.602 & 0.644 & 0.650 & 0.608 & 10,7 \\
\hline Feed intake ( $\mathrm{kg} /$ day) & & & & & & \\
\hline $\begin{array}{l}\text { Conversão alimentar } \\
\text { Feed: gain ratio }\end{array}$ & 1,51 & 1,46 & 1,51 & 1,55 & 1,56 & 6,9 \\
\hline
\end{tabular}

${ }^{1}$ Não-significante (not significant [P>.05]).

${ }^{2}$ Porcentagem de substituição do milho pelo ingrediente teste (Corn replaced percentage by test ingredient).

${ }^{3}$ Ganho de peso obtido com o tratamento/ganho de peso obtido com $0 \%$ de RPFD (Weigth gain obtained with

treatment /weigth gain obtained with $0 \%$ of powdered fruits pulp residue levels).

${ }^{4}$ Estimado pela ingestão diária do RPFD (estimated by powdered fruits pulp residue intake). 
RPFD na dieta, as respostas numéricas para ganho de peso e conversão alimentar pioraram, possivelmente, em razão da redução da granulometria e da textura, quando a ração adquiriu um aspecto mais farináceo. Observações semelhantes quanto à textura do ingrediente e às implicações negativas sobre $o$ consumo da dieta após sua inclusão foram feitas por Moreira et al. (1994) e Barbosa et al. (1999b), que utilizaram milho pré-gelatinizado em dietas de leitões nos períodos de creche.

Dos resultados de desempenho observados na fase inicial-2 e no período total, numericamente, o nível de 50\% de substituição do milho pelo RPFD proporcionou maior eficiência de utilização da dieta. A diferença numérica ficou melhor caracterizada no ganho de peso e na conversão alimentar. Embora não tenha havido diferenças estatísticas nas variáveis aferidas no desempenho, entre as dietas com RPFD, verificou-se que aquela com $100 \%$ de substituição do milho, quantitativamente, propiciou menor desempenho aos leitões. Essa caracterização dos dados ratifica as observações feitas para a fase inicial-1, quanto à granulometria e textura, destacandose a redução do consumo em relação a 50 e $75 \%$, mas não em relação à de menor nível ou sem a inclusão do ingrediente-teste, quando a demanda do alimento foi aumentada com o crescimento.

Ao considerar os resultados médios do período total de creche, também não foram observadas $(\mathrm{P}>0,05)$ diferenças estatísticas entre as variáveis estudadas. Considerando as variações numéricas, como ocorreu nas fases 1 e 2, destacaram-se os resultados obtidos para as dietas com 50 a $75 \%$ do RPFD em substituição ao milho, no desempenho dos leitões. Como ocorreu nas fases anteriores, as dietas contendo o RPFD propiciaram, numericamente, maior desempenho aos leitões. No entanto, aquela com substituição integral do milho ratificou os resultados das fases descritas, provavelmente, em virtude da textura e granulometria inapropriadas para uma ração farelada.

Com base nos resultados do presente estudo, o RPFD torna-se um ingrediente alternativo e um substituto viável para o milho, melhorando as características de dietas de leitões após o desmame. Tratando-se de subproduto e, anteriormente considerado resíduo descartável, o RPFD poderá ser utilizado como redutor do custo de dieta para leitões. Fazendo considerações sobre o custo da alimentação na produção de suínos, Girotto (1990) destacou a significativa participação do milho no custo final de produção, por ser um ingrediente com maior percentual de inclusão na alimentação do suíno. Com relação à presença da farinha de arroz na composição do RPFD, as informações de Costa (2001) apontam o grão de arroz e seus subprodutos como excelentes substitutos ao grão de milho na alimentação de monogástricos, especialmente suínos. O autor destacou o uso da quirera de arroz em substituição integral ao milho da dieta de leitões após o desmame.

Além dos aspectos bromatológicos o ingrediente testado apresentou características atrativas para os leitões. Neste estudo, os benefícios da sua inclusão ocorreram, sobretudo na fase inicial-1, visto que, além da composição química, o RPFD confere melhor aroma e sabor à ração, à medida que seus níveis de inclusão se elevam. Efeito semelhante foi obtido por Barbosa et al. (1999b), ao avaliarem resíduos de bolacha para leitões em fase de crescimento pósdesmame. Com leitões, além do valor biológico, as características organolépticas do ingrediente são fundamentais na elaboração de dietas, graças aos apurados sentidos olfativos e gustativos, nas fases iniciais de crescimento.

Quanto às características organolépticas, o RPFD pode apresentar aroma diferenciado, resultante da maior presença da fruta na sua respectiva estação. A fim de evitar essa variabilidade, no presente estudo adotou-se a uniformização prévia do material que estava estocado em ambiente propício, observando-se, então, o aroma predominante da banana e a manutenção do sabor levemente adocicado da mistura.

As considerações dos resultados $(\mathrm{P}>0,05)$ apresentados, sob diferenças numéricas (percentuais) em todas as fases, visam caracterizar os efeitos que podem ser cumulativos nas fases subseqüentes ao desenvolvimento, conforme destacaram Tokach et al. (1995) e Trindade Neto et al. (2002a), ao avaliarem dietas para leitões nas fases iniciais de crescimento.

Assim, o RPFD pode ser melhor destinado aos produtores de suínos na região onde é obtido, o que anteriormente era feito como descarte industrial sem qualquer perspectiva de receita adicional para a empresa.

\section{Conclusões}

Em dieta farelada, o resíduo de polpas de frutas desidratadas pode substituir totalmente o milho. Numericamente, o melhor desempenho foi obtido com $75 \%$ de substituição na fase inicial-1 e $50 \%$ na fase inicial-2.

\section{R. Bras. Zootec., v.33, n.5, p.1254-1262, 2004}




\section{Agradecimento}

À AJINOMOTO BIOLATINA Ind. e Com. Ltda., à CERIZZA AMBIENTAL Ltda e à Fundação de Amparo à Pesquisa do Estado de São Paulo.

\section{Literatura Citada}

AMIPIG: ileal standardised digestibility of amino acids in feedstuffs for pigs. Paris: Association Française de Zootechnie. 2000. 1 CD-ROM

BARBOSA, H.P.; TRINDADE NETO, M.A.; PETELINCAR, I.M. et al. Coeficientes de digestibilidade e valores energéticos de alguns alimentos para suínos. Boletim de Indústria Animal., v.56, n.1, p.47-52, 1999a.

BARBOSA, H.P.; TRINDADE NETO, M.A.; PETELINCAR, I.M. et al. Efeitos dos processamentos do milho comum e da soja integral no desempenho de leitões desmamados aos 21 dias de idade. Boletim de Indústria Animal, v.56, n.1, p.59-66, 1999b.

BERTOL, T.M.; LUDKE, J.V. Determinação dos valores de energia e balanço de nitroênio de alguns alimentos para leitões na fase inicial. Revista Brasileira de Zootecnia, v.28, n.6, p.1279-1288, 1999.

BELLAVER, C. Ingredientes de origem animal destinados à fabricação de rações. In: SIMPÓSIO SOBRE INGREDIENTES NA ALIMENTAÇÃO ANIMAL, 2001, Campinas. Anais ... Campinas: Colégio Brasileiro de Nutrição Animal, 2001. p.167-190.

BONDI, A.A. Animal nutrition. New York: John Wiley, 1988. $546 \mathrm{p}$.

BUTOLO, A.F. Leveduras vivas e termolizadas na alimentação animal. In: SIMPÓSIO SOBRE INGREDIENTES NA ALIMENTAÇÃO ANIMAL, 2001, Campinas. Anais... Campinas; Colégio Brasileiro de Nutrição Animal, 2001. p.191-198.

COLNAGO, G.L. Composição química e valores de energia de alguns alimentos produzidos no Brasil, para suínos e galinhas poedeiras. Viçosa, MG: Universidade Federal de Viçosa, 1979. 45p. Dissertação (Mestrado em Zootecnia) Universidade Federal de Viçosa, 1979.

COSTA, P.T. O arroz na alimentação animal. In: SIMPÓSIO SOBRE INGREDIENTES NA ALIMENTAÇÃO ANIMAL, 2001, Campinas. Anais ... Campinas: Colégio Brasileiro de Nutrição Animal, 2001. p.77-84.

EMPRESA BRASILEIRA DE PESQUISA AGROPECUÁRIA - EMBRAPA - Centro Nacional de Pesquisa de Suínos e Aves - CNPSA. Tabela de composição química e valores energéticos de alimentos para suínos e aves. 3.ed. Concórdia: 1991. 97p.

FURLAN, A.C.; MANTOVANI, C.; MURAKAMI, A.E. et al. Utilização de farelo de girassol na alimentação de frangos de corte. Revista Brasileira de Zootecnia, v.30, n.1, p.158164, 2001.

GIROTTO, A.F. Custo de produção de suínos para abate: anexo 40. EMBRAPA- Centro Nacional de Pesquisa de Suínos e Aves - CNPSA, 1990. 2p. (Comunicado Técnico)

GOMES, P.C.; ZANOTTO, D.L.; GUIDONI, A.L. et al. Uso do farelo de canola em rações para suínos na fase de crescimento e terminação. Revista Brasileira de Zootecnia, v.27, n.4, p.749-753, 1998.
KIDDER, D.E.; MANNERS, M.J. Digestion in the pig. England: Kingston Press, 1978. 201p.

MATTERSON, L.D.; POTTER, L.M.; STUTS, M.W. et al. The metabolizable energy of feed ingredients for chikens. Storrs: Connecticut University, Agricultural Experiment Station. 1965. 11p. (Research report)

MOREIRA, I.; ROSTAGNO, H.S.; TAFUTY, M.L. et al. Uso do milho processado a calor na alimentação de leitões. Revista Brasileira de Zootecnia, v.23, n.3, p.412-421, 1994.

NATIONAL RESEARCH COUNCIL - NRC. Nutrients requirements of swine. 10.ed. Washington: National Academy of Science. 1998. 189p.

PATIENCE, J.F.; THACKER, P.A.; LANGE, C.F.M. Swine nutrition guide. 2.ed. Saskatoon: Praire Swine Centre Inc., 1995. 274p.

PEKAS, J.C. Versatile swine laboratory apparatus for physiologic and metabolic studies. Journal of Animal Science, v.27, n.5, p.1303-1306, 1968.

PEKAS, J.C. Digestion and absorption capacity and their development In: MILLER, E.R.; ULLREY, D.E.; LEWIS, A.J. (Eds.) Swine nutrition. Stoneham: ButterworthHeinemann, 1991. p.37-73.

ROSTAGNO, H.S.; NASCIMENTO, A.H.; ALBINO, L.F.T. et al. Tabelas brasileiras para aves e suínos. Composição de alimentos e exigências nutricionais. Viçosa, MG: Universidade Federal de Viçosa, 2000. 141p.

TOKACH, M.D.; PETTIGREW, J.E.; JOHNSTON, L.J. et al. Effect of adding fat and (or) milk products to the weanling pig diet on performance in nursery and subsequent grow-finishing stages. Journal of Animal Science, v.73, n.12, p.33583368, 1995.

TRINDADE NETO, M.A.; LIMA, J.A.F.; FIALHO, E.T. Avaliação química e biológica do farelo de glúten de milho (FGM), com suínos em cresimento e terminação. Revista da Sociedade Brasileira de Zootecnia, v.23, n.3, p.497-505, 1994.

TRINDADE NETO, M.A., BARBOSA, H.P., PETELINCAR, I.M. Farelo de soja, soja integral macerada e soja micronizada na alimentação de leitões desmamados aos 21 dias de idade. Revista Brasileira de Zootecnia, v.31, n.1, p.104-111, 2002a.

TRINDADE NETO, M.A.; PETELINCAR, I.M.P.; BERTO, D.A. et al. Resíduo de polpas de frutas desidratadas na alimentação de leitões em fase de creche. In: REUNIÃO ANUAL DA SOCIEDADE BRASILEIRA DE ZOOTECNIA, 39., 2002, Recife. Anais... Recife: Sociedade Brasileira de Zootecnia/Technomedia, [2002b]. CD-ROM. Nutrição de não ruminantes. 10/16

STATISCAL ANALYSES SYSTEM - SAS. SAS user's guide: statistics. Release 6. Cary: 1993. 943p.

VEUM, T.L. Feeding neonatal pigs In: MILLER, E.R.; ULLREY, D.E.; LEWIS, A.J. (Eds.) Swine nutrition. Stoneham: Butterworth-Heinemann, 1991. p.483-495.

Recebido em: $12 / 03 / 03$ Aceito em: 12/11/03 